\title{
The Use of Apps in Foreign Language Education: A Survey-Driven Study
}

\author{
Caleb Powers ${ }^{1 *}$
}

\begin{abstract} prioritize facility of use, accessibility, and price when deciding whether to keep an app or not.

\section{Keywords}

Computer-Assisted Language Learning - Duolingo - Babbel —Rosetta Stone

${ }^{1}$ Department of World Languages, Literatures and Cultures, University of North Texas

${ }^{*}$ Faculty Mentor: Dr. Lawrence Williams
\end{abstract}

The purpose of this study was to understand why advancements in technology were not being implemented in foreign language education and how those new technologies could improve foreign language education. This study surveyed 114 foreign language students in order to gain information on how they used technology to learn a foreign language. The questions on the survey related to the topics of attitudes toward technology in general, the students' accessibility and academic/personal use of technology tools, and their awareness and usage of specific foreign language learning mobile apps. It was found that apps like Duolingo, Rosetta Stone, and Babbel are more often used than other language learning apps, they fulfill crucial elements of education, and students

\section{Contents}

\section{Background}

2 Computer-Assisted Language Learning (CALL) 1

2.1 New Technologies and Language Learning..........2 Computer-Assisted Learning • Teaching with CALL

3 Methods

3.1 Survey

3.2 Participants.

4 Results

5 Discussion

6 Conclusion

Author Biography

References

\section{Background}

Edward R. Murrow, a renowned broadcast journalist, once spoke on the use of the television as a pedagogical tool: "This instrument can teach, it can illuminate, yes, it can even inspire. But, it can do so only to the extent that humans are determined to use it to those ends. Otherwise, it is merely lights and wires in a box." $[1,121]$ Incredible advancements in technology seem to have saturated our everyday lives, but in foreign language education, there is an unexplained lack of such progress. The following questions guide the present study: Why are new advancements in technology not being implemented more into foreign language education today? In what ways are language apps intended to improve second language acquisition? Are the apps not being received well by the users? Do users think there is something missing in language apps?

Even though computer-assisted language learning (CALL) ${ }^{1}$ successfully produces fundamental elements of language education, classrooms seem to be cemented in ancient practices, unable to advance with the times. Pedagogical technology is not being used as effectively as it should be.

\section{Computer-Assisted Language Learning (CALL)}

Currently, there is not an extensive amount of survey-based research on students' use of technology in the foreign language classroom. The following is an amalgamation of some articles that began research in this developing area of study.

Many studies of learning methods gather that there are crucial elements that improve foreign language education, interaction being recurrent. Gallardo del Puerto and Gamboa conducted a study in which teachers expressed the learning methods they perceived to be the most effective. The majority claimed that "oral interpersonal communication" and "group work or role-playing" were indispensable.[2, 145] If collaboration and social interaction are among the most crucial elements of developed education, then the ways in which students use technological applications should reflect that.

MacDonald asserts in her article that there are three pivotal elements essential to foreign language progress. One,

\footnotetext{
${ }^{1}$ The author is aware that the term Computer Assisted Language Learning (CALL) may be antiquated and that there are other terms for this area of study but chose to include this term for the sake of notoriety.
} 
the learner must experience target language that is authentic and must be successfully understood. Two, the likelihood of comprehension increases when the target language is actively perceived. And three, the likelihood of consciously perceiving that information increases during social interaction. Therefore, according to MacDonald, to fully apprehend a foreign language, the content must be limpid and actively pursued through interaction with classmates. By using computermediated education in the classroom, each of these crucial elements can be achieved.[3] A student can employ an application to communicate with someone and experience the language while simultaneously using another to ensure their comprehension.

Unbeknownst to older generations, the Internet can be used to execute superior education. Computer-Assisted Language Learning (CALL) can be explained as simply as a learner using a computer to improve their language.[2] Because of the vast amounts of information on the Internet, students' opportunities for growth expand significantly. In MacDonald's article, she asserts that the Internet has "the ability to focus students' attention."' $[3,457]$ to receive and comprehend target language, therefore encouraging development. Engaging in an online activity can produce larger amounts of knowledge than a teacher alone would be able to provide and using the Internet benefits students by allowing them to access knowledge and credible target language while practicing social interaction and useful computer skills through relationships with native speakers.

The Internet has proven itself to be the next frontier in education with the potential for unprecedented opportunities. Salaberry (2001) wrote an essay on the use of technology in foreign language acquisition in which he referenced a study asserting that the success of computer technology is directly related to the implementation of "specific pedagogical tasks."[4] that are unachievable in other environments. The use of computer-assisted learning aids students while incorporating a plethora of vital elements. Lindenau, an essayist on the relationship between teachers and technology, asserts that existing and emerging technologies can improve the quality of education:

An educational system limping along at the blackboardand-textbook stage of communication providing few, if any, opportunities for understanding technology will not be able to graduate people who can respond successfully to their own needs let alone to the technological requirements of an advancing society in an increasingly interdependent world.[1, 119]

Just as quotidien use of the Internet can unite people from across the globe, computer-assisted language learning can foster connections that were insurmountable before between speakers no matter their locale. Gallardo del Puerto and Gamboa assert that CALL provides access for individuals "who would otherwise be separated by time or space."[2] Archives all over the world are digitizing their records, allowing for more accessible knowledge. These networks, unattainable before, should be exploited to develop students' language and cultural comprehension.

This would be an easy feat for millennials as they are renowned for their proficiency and intimacy with technology. Their affinity can be harnessed in foreign language education. Salaberry delineates that, while some technologically assisted focus groups test the same as their traditional counterparts, they are "far superior in positive attitude." $[4,49]$ Not only are they benefitted logistically, but also students in foreign language classrooms are generally more excited to learn when technology is involved and believe that it helps improve their work.

Gallardo del Puerto and Gamboa observe that "the internet environment contributed significantly to students' motivation towards the study of the foreign language" and provides a "sense of belonging to a community" because it "encourages students to develop knowledge through collaboration." $[2,146]$ With mobile technology, "learners can study or practice manageable chunks of information in any place on their own time, thereby taking advantage of their convenience." $[5,13]$ Motivation is crucial in the classroom and if computer use encourages students to attend class, educators should exhaust this advantage. Gallardo del Puerto and Gamboa constructed a list of factors provided by educators for using information and communication technologies (ICTs). It was found that ICTs can be used 'for students' convenience, to present language in varied ways...to connect with native speakers and the target culture...to advance students' learning processes...to motivate students...to teach specific skills, to facilitate information search, to make the availability of materials easier...and to facilitate collaborative learning and group interaction." $[2$, 141] No other technology has ever brought as many versatile elements to foreign language education as the Internet, and yet, it is not being utilized to its fullest extent.

\subsection{New Technologies and Language Learning}

During the past 20 years, extensive research has been conducted on specific tools capable of changing foreign language education, but if the applications used in these studies are not implemented in the classroom, no influence can be expected. Van Hove, Vanderhoven and Cornillie, researchers in foreign language technologies, understand that "the full potential of these new media often remains underexploited" $[6,53]$ so they conducted a study to evaluate the effectiveness of the tablet as a foreign language vocabulary learning tool. The study investigated three modalities: "multiple choice, typing, and writing by means of a stylus." The results showed that those subjects who typed or wrote "obtained higher scores on spelling and use of diacritics" than those who utilized the multiple-choice method. Even though it often produces higher scoring results, they concluded that multiple choice questioning is flawed because it does not require recall, but rather only recognition. However, benefits could derive from using multiple-choice 
modalities if "competitive alternative answers are provided to stimulate high-level processing." $[6,54]$ This research is critical as it does what all professionals in foreign language education should do-it questions how to best use technology.

Research into advanced methods of language education should continue, but existing technologies should be engaged. MacDonald introduced Postcards an online, collaborative activity. This application allowed students to practice target language while experiencing the culture of their foreign colleague. Using assigned grammatical elements, the users wrote digital postcards to their partners and gave constructive feedback and advice, thus making this a "collaborative, knowledgebuilding, students-helping-students experience."[3] Applications like this have the potential to impact foreign language education immensely but must be utilized to do so.

\subsubsection{Computer-Assisted Learning}

As teaching methods become more developed, technology gets woven into the framework of education more often. ComputerAssisted Learning (CAL) has been introduced to pharmacology to demonstrate arterial blood pressure in dogs [7] and has been integrated into the education of science, technology, engineering and mathematics to better prepare students for real world experiences.[8] But how are these developments impacting foreign language education?

Previous survey-based studies have influenced this study. Winke and Goertler's research found that students do not have competent training in or access to technologies necessary for CALL success "because of the specialized nature of CALL tasks." $[9,482]$ Williams, Abraham, and Bostelmann conducted a study to better understand "students' preferences and practices related to new technologies and digital literacies.”[10,29]

\subsubsection{Teaching with CALL}

With these advancements in technology, the role of the foreign language educator must evolve as well. MacDonald states that a shift is necessary - from being a "'sage on the stage' to a 'guide on the side"' (p. 455). Instead of simply delivering information, a teacher should "create interactive communication situations that empower students." [3, 455] Educators should use the tools provided in order to create the necessary conditions and elements that better the level of education while also motivating their students. Gallardo del Puerto and Gamboa declare that the teacher should be a "guide of group tutorials and a promoter of cooperative work." $[2,145]$

Some believe that technology has the capability to replace teachers, but this concept is antiquated and misleading. The success of CALL is dependent on "learner training and supervision" $[2,139]$ provided by teachers. The educator is an indispensable factor as they assist their students, forge ideal learning environments, and integrate technology into their existing curriculum.

According to teachers, technology can improve the quality of education but to the contrary, it is not used as frequently as it should. Gallardo del Puerto and Gamboa confirm: "al- though teachers believe that second language acquisition is primarily driven by social interaction, they seldom use computers as a means to foster collaboration or interaction." $[2$, 137] Educators acknowledging that technology could advance schooling but not implementing it is deceiving. So, if teachers have access to tools that can greatly impact education, why do they continue to use minimal or antiquated pedagogical strategies?

Many components have led to the dearth of technology in the classroom, but one is prevalent: training. The lack of training in information and communication technologies produces obstacles when striving to implement computerassisted learning. Teacher training has been described as "a precondition for CALL success" $[2,140]$, yet colleges and universities do not provide adequate instruction in how ICTs can be administered nor of their benefits. They neglect to equip their teachers with the expertise on how to understand technology.[1]

\section{Most educators disclose that they are "dissatisfied with}

CALL training" $[2,140]$ due to the antiquated nature of the technologies employed in training. Teachers are ineptly using these appliances in the classroom; their use of ICTs "has not reached its optimal point" and they will "not exploit all the opportunities offered by technology if they keep on relying upon informal methods of preparation." Program organizers need to revise their training as to "adequately address today's technologically advanced language classroom" and if educators do not possess the knowhow, they cannot produce the necessary environment to best instruct their students.

Teachers need the most guidance with the fusion of these emerging technologies and their curriculum. Lindenau explains: "Libraries and resource centers house technologies; their purpose is to provide not to integrate technology into the learning process. It is with integration that teachers need help." $[1,121]$ Without training, foreign language educators most often utilize basic technologies. With Gallardo del Puerto and Gamboa's research, it was found that the most recurring uses of technology were "teacher-produced documents and assignment submissions." $[2,144]$ These activities are not collaborative; therefore, they are not as beneficial to foreign language education as their communicative counterparts. It is disconcerting that the Internet can be referred to as a resource "only limited by one's imagination and creativity" $[3$, 461] but the most outstanding application a teacher could propose is a TurnItIn submission. Even if provided with tools, teachers are not able to utilize them to their fullest capability and can only act on what they know, thus fortifying that educators need training on technologies that improve language acquisition.

Teachers' assorted experiences using technology in foreign language education have lead to opinions on which are the most effective activities. When asked about which scenarios were actually strengthened by computers, "many teachers emphasized the role of individual activities" $[2,145]$ like "autonomous learning," research, and grammar exercises. How- 
ever, when the same teachers were asked which scenarios they would like to use but have yet to receive training over, individual activities emerged yet again. These results are alarming; teachers disclosed that they do not have training in what they think is the most effective venue of computer-assisted language learning. Even more, recalling the crucial elements for developed learning, individual activities were not considered the most effective. In fact, the opposite was true. These educators are misguidedly pursuing individual tasks only because of their ignorance to the abundance of activities their students could benefit from if technologies were properly implemented in the classroom.

Another major issue derives from budgetary restrictions. Without sufficient funding, adequate technology cannot be purchased to implement in the classroom. When a university spends millions of dollars to build a football stadium, but their classrooms have defective desks and archaic chalkboards, it says something about the societal belief regarding advancements in education. The distribution of funding needs to be reevaluated to better reflect a university's priorities-education.

The availability of equipment, time management, and the inability to remain abreast of emerging technologies also yield hindrances that delay the realization of the optimal classroom.[1] It is the responsibility of the administrators to remove these barriers to provide the best education possible to their students just as it is the duty of the teacher to report the effects of an underdeveloped classroom.

\section{Methods}

\subsection{Survey}

To assess the appeal and adequacy of foreign language learning apps, a paper- based survey was conducted with 114 foreign language students. A decision was made to administer the survey on paper and in person to ensure more and immediate responses and also to have the opportunity to individually inspect each survey for quality and validity. ${ }^{2}$ The survey had four sections-Background, Accessibility to Technology Tools, Apps, and Follow-up Questions. ${ }^{3}$

In the background section, the students were asked their age, their student standing, their first language and what foreign language courses they were currently taking. They were also asked some background questions concerning technology such as how they would describe themselves as technology users, what their favorite technological invention of the past decade was and even when they got their first cell phone. This section and the following were inspired by survey-driven research conducted by Winke and Goertler[9] and Williams, Abraham, and Bostelmann.[10]

This background section gives insight into who these students are and how they view technology in general, which aids

\footnotetext{
${ }^{2}$ The author and/or the thesis adviser recruited participants and administered the surveys.

${ }^{3}$ For the full survey, see the Appendix.
}

in understanding their responses to the following questions. In the second section, they were asked to mark if they used particular tools like a computer, a cellphone or a television every day, sometimes, rarely or never. Then, they were asked to mark if they used more specific tools such as Facebook, podcasts, or DVDs in their personal life, in their language courses, in their non-language courses, not at all, or if they thought it would be useful in their language courses. The data from this section will provide the research a secondary source of background information on the students' current uses of technology.

Then in the app section, the survey provides three different lists of apps and asks the students to mark if they have used the app's free version, subscription version or not at all. The first list is of language course apps whose main purpose is to teach the grammar, vocabulary, and syntax of a language. In order to decide which apps were best to include, online articles ranking the best language learning apps were referenced.[11, $12,13,14]$. The following apps were on that list.

Founded in 2007, Babbel was the first language learning app and currently has more than one million active subscribers. With over 8,500 hours of content in 14 languages, Babbel uses immersion, proven cognitive methods, human voice and speech recognition to teach its users.

Bernhard Niesner created busuu in 2008 in hopes of preventing the Cameroonian language Busuu from going extinct. Today, they offer 12 different languages and have 80 million learners worldwide. Busuu teaches reading, writing, speaking and listening and connects users with native speakers of their target language.

Drops is a language learning platform that utilizes augmented reality to teach its two million users fundamental vocabulary from 28 languages. Learners are given one fiveminute session a day to apprehend new words using the environment surrounding them.

Duolingo's manifesto is to make language education fun, accessible, and free. Their app has over 200 million users and employs a plethora of modalities to ensure maximum retention. The app was created to act as an entertaining game to entice learners to continue their lessons.

Fluenz is a guided program that focuses on learning relevant and useful content and mimics a personalized tutoring session. Users can choose to buy a learning package in one of seven languages, including Mandarin Chinese.

Lingo Play allows users to choose to either study or play against each other in a gamified version of language learning. With features like online tournaments, vocabulary lessons, and certification, Lingo Play allows learners to gain access to a foreign language in many different modalities.

Although LiveMocha is no longer operational, it was a useful program loved by many users. It featured detailed instructional content in six different languages, conversational exercises to build proficiency, and employed strategies to improve motivation.

Living Language is a subscription-based learning platform 
that offers courses in 52 languages and specialized courses such as "On the Job" and "Business." They focus on confidence and ensure their users practice through conversation in various scenarios.

For 11 years, millions of language learners all over the world have used Mango Languages which offers courses in more than 70 languages. Not only do they have traditional courses, but they also have culturally specific lessons and even movies to better student comprehension.

Mondly makes fluency more attainable. The app employs features such as augmented reality, a kid friendly version, and even a version for businesses but the most enticing feature is the virtual reality mode. With the help of a headset, users can travel virtually across the globe and experience various environments and situations that allow them to practice their language.

Pimsleur is based on the research of Dr. Paul Pimsleur, a scientist whose method has been proven to move vocabulary from short-term to long-term memory. The program varies the ways in which the students learn so they are interested, motivated, and retain lessons at a higher rate.

In 2004, Rocket Languages was founded and has since accrued over one million users. The program features interactive audio lessons, voice recognition, and cultural lessons. They claim their method allows students to learn a language faster than other programs.

Rosetta Stone is an award-winning language service that offers lessons in over 30 languages to millions of users worldwide. They offer their services to educators and businesses and to the individual learner. As an organization, one of their goals is to help prevent indigenous languages from going extinct.

Spanish SOLO is a storyline-based Spanish learning program that allows users to follow John Daniels as he goes to Buenos Aires to learn Spanish. The gamification aspect keeps learners coming back while the speech recognition ensures they are correctly speaking the language.

Using science to guide their methods, Transparent Languages makes language learning faster with more reliable results in over 100 languages.

Lastly, Yabla is an immersion-style language learning app that offers six languages and features tools such as duallanguage subtitles, multimedia experiences, and speed controls.

In the concluding section, the students were asked a freeresponse question to better understand their reception of the aforementioned apps: What are one or two determining factors that make you decide if you want to use a language learning app or not? The students were also given the choice to participate in a semi-structured interview where they would be asked questions based on their responses to the survey. The following questions were asked in each survey:

1. How would you characterize your attitudes toward technology in general?
2. Which types of technology do you like the most?

3. Which types of technology do you like the least?

4. How do you currently use technology to learn a foreign language?

5. Which technologies do you use in everyday life that you do not use for school (in general)?

6. Which technologies do you use in everyday life that you do not use for language learning?

7. What is your favorite app for school-related purposes?

8. What is your favorite app for language learning-related purposes?

9. Which apps have you heard of yet never tried?

10. Why haven't you used them?

11. Which apps have you tried but not liked at all?

12. What determining factors decide if you keep the app or not?

13. What feature did you find lacking in an app? Which app?

14. What experience did you find lacking in the app? Which app?

15. What level are you in French?

16. Why are you taking the language courses you are in right now?

17. What improvement would you recommend for a specific app?

Due to the nature of (paper-based) survey research, five surveys were excluded for a variety of reasons. Two of the surveys had issues with the items involving age. One respondent did not provide an age (A1) and in the related item (A7), the age at which this person indicated they received their first cell phone was not legible. It could have been interpreted as 304 years old, $30 \mathrm{y}$, where "y" is short for "years," or 30.4, where the decimal was not marked dark enough to see. Because a definitive answer could not be determined, this survey has been excluded from the study. The other survey was excluded because the respondent wrote in that their age was 7.5 months old, which is improbable. In the remaining three surveys that were excluded, each respondent indicated that they have used the free version for every single app in items $\mathrm{C} 1, \mathrm{C} 2$, and C3. As this is highly unlikely and since several of the apps, including Pimsleur, Transparent Languages, and Yabla, do not even offer a free version, the sincerity of the survey is null. 


\subsection{Participants}

The survey sample included 114 students from Elementary level to Advanced level6 French classes at the University of North Texas. At UNT, the Elementary level spans the first year of the four-year program, while the Intermediate level is the next year, both of which focus on grammar, phonetics, reading, composition, and oral-aural practice. The last two years are Advanced level courses. The following tables and graphs are results from section A of the survey.

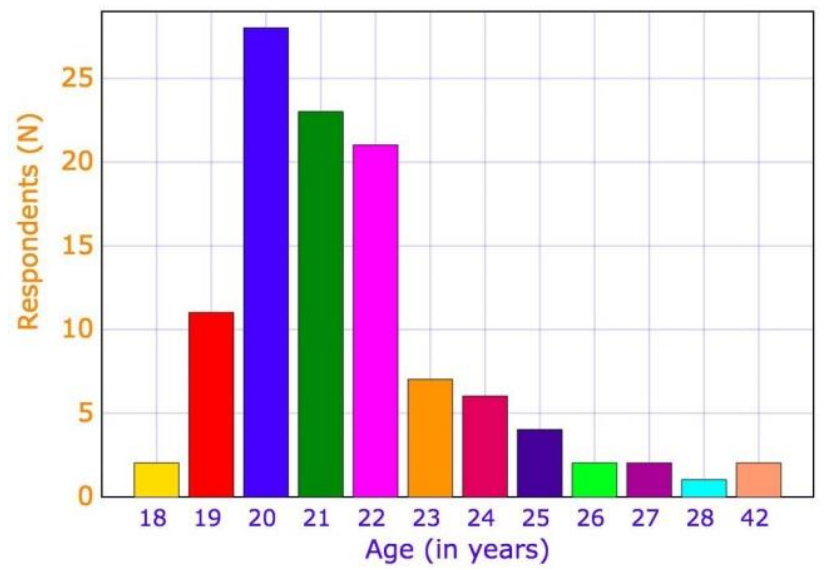

Figure 1. Age of Respondents

The average age of the respondents was 21.78 years old and the average age at which the respondents received their first cell phone was 12.77 .

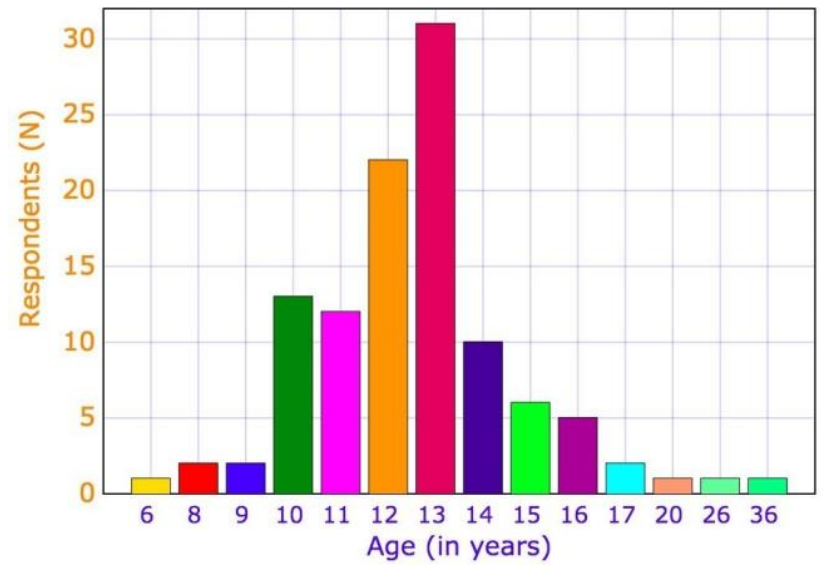

Figure 2. Age at Which Respondents Received Their First Cell Phones

The following tables list some respondent demographics.

Table 1. Student Standing

\begin{tabular}{lcccc}
\hline & Freshman & Sophomore & Junior & Senior \\
\hline Percent & $7.5 \%$ & $27.1 \%$ & $36.5 \%$ & $28 \%$ \\
Number & 8 & 29 & 39 & 30 \\
\hline
\end{tabular}

Additionally, one graduate student was included in the survey ( $0.9 \%$ of survey respondents).
Table 2. First Language

\begin{tabular}{lccc}
\hline & English & Spanish & Other \\
\hline Percent & $80.6 \%$ & $5.6 \%$ & $13.9 \%$ \\
Number & 87 & 6 & 15 \\
\hline
\end{tabular}

Table 3. Course Level

\begin{tabular}{lccc}
\hline & Beginning & Intermediate & Advanced \\
\hline Percent & $37.6 \%$ & $46.8 \%$ & $33 \%$ \\
Number & 41 & 51 & 36 \\
\hline
\end{tabular}

\section{Results}

Semi-structured interviews were conducted with three Advanced level students of French. Interviewee A was a selfdescribed "proficient" level French major who wanted to be a translator. This person "grew up in the time where technology was quickly advancing." The second participant was Interviewee B, an "advanced conversational" level student of French and who was working on earning a Professional French Certificate. Interviewee C "did a Bachelor's degree in France," and has "been taking French for ten years."

When asked about their relationships with technology in general, the students responded with "very open" and "positive" to even "a means of entertainment and convenience." Interviewee $\mathrm{C}$ believed that technology is "the way the world is moving and we need to keep up with it." Interviewee B stated that it is important to "seek new ways to use technology very often."

The participants were asked what types of technologies they liked most and two responded, "I use my phone the most," and "I mostly use my smartphone for everything since it does everything now." The third student replied with "apps on my phone."

The interviewees also discussed the ways in which they currently used technology to learn a foreign language and which was their favorite app for language learning purposes. Interviewee A stated they "use the Quizlet app so that [they] can study the flashcards," and that they "use flashcards for ... all of [their] classes." They liked "Quizlet because [they] just [made their] own flashcards." Interviewee B responded that they use "Duolingo and Mango Languages" and that they are a "big fan" of Ankiapp - which is their favorite app. Interviewee $\mathrm{C}$ had "Duolingo on [their] phone, which is kind of helpful" and used Google Translate if they "[needed] to find a word for [their] French class" but "Quizlet [was their] favorite app for school related purposes."

When asked what apps they had heard of but never tried, two respondents replied with Babbel and Rosetta Stone and one of them stated that they "[knew] Babbel [costed] money and [they didn't] want to pay for it when [there were] free options." The third participant stated, "I like Mango Languages more than Babbel. I thought Babbel was a watered-down version of Duolingo," and, "I've read reviews on each of [the 
apps] and they don't really concentrate in the languages that I study," That same participant also did not try other apps because they were "pretty content with Duolingo."

The students shared their determining factors that decided whether they kept an app or not. There were varied answers like, "usability," "aesthetics," "how it loads," "user interface," "ease of use," and "convenience," but one response was universal: price. One respondent commented that they were "less likely to use" the subscription version of an app and another stated that they were not going to pay for an app while they were already paying for college.

All three respondents commented on Duolingo, one saying "a big thing that [they] like about Duolingo is that it's free forever." The other two students critiqued Duolingo. One disclosed that they wished there were "one-on-one" or "face-to-face tutoring." The other reported that they thought Duolingo should have a grammar element because it "teaches you phrases but not how to make your own phrases." Interviewee B added that "regardless of the amount of money that go into [Rosetta Stone and Babbel], it doesn't come out looking really good" and they are "not attention-getting." They would like to see Duolingo introduce a vocabulary review section "at the end of each module" to imitate the "review of vocabulary at the end of the chapter" in their textbook. They also thought it would be "really effective" to conduct "one-on-ones" between customers and administration to discuss "the specific things that they would like to see change."

\section{Discussion}

Recalling the elements that have the potential to improve the acquisition of a foreign language, social interaction, roleplaying, and convenience were discussed, among others. But how exactly can apps fulfill those crucial characteristics? Apps like Tandem provide authentic target language, social interaction, and the transcendence of time and space by allowing users to converse directly with native speakers. Babbel and Mango feature simulated conversations that incorporate role-playing and Spanish SOLO's storyline motivates students to invest themselves. Duolingo has "gamified" language learning to improve motivation and positive attitude and create a community of learners all by implementing a point system and the ability to view friends' point rankings. Quizlet, Google Translate and many more of these apps keep convenience in mind when designing their programs. Drops and Mondly employ augmented reality which three respondents indicated they thought was the greatest technological invention of the past decade. Language learning apps are built with the intention to improve foreign language education and employ many of the crucial elements previously discussed, yet they are not being implemented in the classroom.

In response to the question of why students are not using language learning apps, it is important to eliminate counterarguments. Using the average age of the respondents, the majority of the respondents have had a cell phone for about half of their lifetime, $98.2 \%(n=107)$ use it every day, and $94.7 \%$
(108) indicated that they really like technology. All three interviewed students elaborated that their favorite technologies were their smartphones and the apps on them. Therefore, one can conclude that the lack of technological integration into foreign language learning is not due to students' aversion to technology. So what exactly is hindering the popularization of these apps?

Price is an important aspect that has to be taken into consideration. Being that $29.7 \%(n=30)$ of respondents indicated that price was a determining factor of whether they use an app or not and all three interviewed participants urged that price was a primary factor, language app developers must acknowledge that language students prioritize price over other features. Also, foreign language educators, as previously stated, are underfunded and, therefore, are not able to employ programs that are subscription based in their classrooms.

Another facet of the issue to consider is the accessibility. If an app is not easy to access or use, it deters potential students from committing to the program. About $37 \% \quad(n=38)$ of respondents indicated that this was an important issue that determined their participation. Interviewee B even stated that "usability is ... number one" and the other two participants also mentioned ease of use and convenience as big motivators.

A possible explanation could be that there is something missing from the apps. If students want an interaction or grammar element, the developers need to comply with popular demand. Or if it is "not attention-getting," something needs to change. In order to better determine the beliefs of students relating to this topic, more research would have to be conducted. A big piece to figuring out why language learning apps are not being implemented into varying modes of education is the responsibility of the app developers-listening to their customers.

\section{Conclusion}

When the phonograph was first introduced to language learning, it was seen as only a pronunciation practice tool and " "nothing else could be asked of it."'[15, 118] A few years later, it was found to aid in understanding intonation and bettering motivation, thereby proving it had not been used to its fullest capability.[4] Even though this usage expansion of the phonograph occurred in the early 18th century, its lesson persists today. More research into the potential uses of current technology is necessary to best utilize modern tools. With more complex and multifaceted technology emerging every day, the potential must be explored.

In order to reach the goal of a more developed language learning system, educators need to be trained in innovative technology applications. Once teachers are equipped with the necessary information, they can provide professional advice from the perspective of the classroom to improve the actual implementation of the proposed technologies. As for the apps, developers need to ensure that accessibility, facility of use, and price take precedence since these are the elements that motivate students to use their product. Ultimately, it is 
necessary to move past considering technology as "lights and wires in a box."[1] and undertake the arduous work that is crucial to advancement.

\section{Author Biography}

Caleb Powers graduated in Spring 2018 with a Bachelor of Arts in French with a minor in Spanish. During his time at the University of North Texas, he was involved with organizations on campus and in the classroom. Caleb is from Mont Belvieu, $\mathrm{TX}$ and plans on a career higher education in French.

\section{References}

[1] Suzanne E Lindenau. The teacher and technology in the humanities and arts. The Modern Language Journal, 68(2):119-124, 1984.

https://doi.org/10.1111/j.1540-4781.1984.tb01552.x

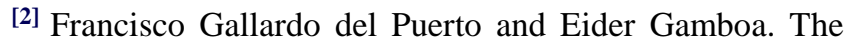
evaluation of computer-mediated technology by second language teachers: Collaboration and interaction in call. Educational Media International, 46(2):137-152, 2009. https://doi.org/10.1080/09523980902933268

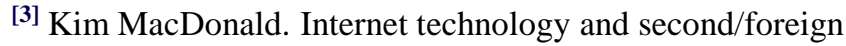
language education: Activities for the classroom teacher. Canadian Modern Language Review, 59(3):455-462, 2003.

https://doi.org/10.3138/cmlr.59.3.455

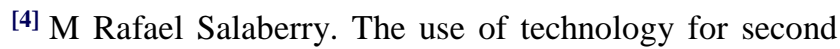
language learning and teaching: A retrospective. The Modern Language Journal, 85(1):39-56, 2001.

https://doi.org/10.1111/0026-7902.00096

[5] George M Chinnery. Emerging technologies. going to the mall: mobile assisted language learning. Language, Learning \& Technology, 10(1):9-16, 2006.

[6] Stephanie Van Hove, Ellen Vanderhoven, and Frederik Cornillie. The tablet for second language vocabulary learning: Keyboard, stylus or multiple choice. Сотиnicar, 25(50):53-63, 2017.

https://doi.org/10.3916/C50-2017-05

[7] Parama Sengupta, Abhishek Sharma, and Nina Das. Is there any benefit of integrating computer-assisted learning with conventional teaching format in pharmacology to demonstrate the effects of different drugs on mean arterial blood pressure in an anesthetized dog?: A comparative study. Journal of Natural Science, Biology, and Medicine, 8(2):181, 2017.

doi: 10.4103/0976-9668.210013

[8] Shu-Hsuan Chang, Ai-Chiao Ku, Li-Chih Yu, TsungChih Wu, and Bor-Chen Kuo. A science, technology, engineering and mathematics course with computer-assisted remedial learning system support for vocational high school students. Journal of Baltic Science Education, 14(5), 2015.

[9] Paula Winke and Senta Goertler. Did we forget someone? students' computer access and literacy for call. Calico
Journal, 25(3):482-509, 2008.

[10] Lawrence Williams, LB Abraham, and Evan D Bostelmann. A survey-driven study of the use of digital tools for language learning and teaching. Digital Literacies in Foreign and Second Language Education, pages 29-67, 2014.

[11] J. Duffy. The best language-learning software of 2018. https://www.pcmag.com/article2/0, $2817,2381904,00$. asp, 2018. Accessed: 2018-0322.

[12] N. Ekstein. Here is the best language learning app for you. https://www.bloomberg. com/news/articles/2017-07-21/

five-language-learning-apps, 2018. Accessed: 2018-07-21.

[13] S. Fisher. The 7 best free language learning apps. https://www. thebalance.com/ the-7-best-free-language-learning-apps, 2018. Accessed: 2018-03-14.

[14] S. Hill. The 5 best apps for learning a foreign language. https://wWw.digitaltrends.com/ mobile/best-apps, 2018. Accessed: 2018-04-25.

${ }^{[15]}$ Charles C Clarke. The phonograph in modern language teaching. The Modern Language Journal, 3(3):116-122, 1918. 